\title{
Enhanced Gain Square Monopole Antenna using FSS Layer
}

\author{
Gaurav P. Prabhu Mahambre \\ Department of Electronics and Telecommunication \\ Goa College of Engineering \\ Ponda, India
}

\author{
Amita Dessai \\ Depeartment of Electronics and \\ Telecommunication \\ Goa College of Engineering \\ Ponda, India
}

\begin{abstract}
In this paper, a $1 \times 2$ array of square monopole antenna using a Frequency Selective Surface layer having a high gain is proposed. The FSS layer reflector is placed below the microstrip line fed monopole antenna. The monopole and FSS layer are designed on duroid and FR4 substrate respectively. The antenna is operated on $2.3 \mathrm{GHz}$ WiMAX band frequency. The antenna structure dimensions are $213 \mathrm{~mm} \times 213 \mathrm{~mm}$.
\end{abstract}

\section{Keywords}

Square Monopole Antenna; FSS layer; high gain antenna; WiMax bands

\section{INTRODUCTION}

Ultra- Wideband (UWB) technology supports numerous applications in electronics product, impulse radio, communication system and radar. The wideband antennas in can support several different service bands in the ultra-wideband (UWB) service band, such as WLAN, Worldwide Interoperability for Microwave Access (WiMAX:2.30$2.39,2.50-2.69,3.4-3.8$, and $5.72-5.85 \mathrm{GHz}$ ), and Satellite Digital Multimedia Broadcasting (S-DMB: 2.605-2.655 GHz)[2-3].

Frequency Selective Surfaces (FSS) comprise of an array of similar type of elements or cells repeated in the two dimensional geometry with known periodicity. These elements may be patches or slots. Planar and Frequency Selective Surface (FSS) are used to increase the gain of UWB antenna. Their properties can be engineered to exhibit band-pass, band-stop, low-pass, or high-pass characteristics depending on design [4-6].

FSSs can be energized by incident waves or by individual source for each element of FSS. The array excited by earlier method is called passive array or FSS while the array excited by second method is termed as active array or FSS. FSS exhibits the properties of a band stop filter where the electromagnetic waves incident on it are reflected [6].

The monopole antennas gives high impedance bandwidth with good radiation pattern in azimuthal plane. Monopole antennas are a special case of microstrip antenna configuration wherein the ground plane is located at infinity. A patch is fabricated on dielectric substrate. Beyond the substrate it can be assumed that a very thick air dielectric substrate $(\varepsilon r=1)$ exists. It makes a microstrip antenna configuration on a thick substrate that gives high bandwidth [4-6].

In this paper a $1 \times 2$ array of square monopole antenna using FSS as a reflector is proposed. The antenna is simulated at $2.3 \mathrm{GHz}$. The following sections present the antenna geometry, design theory, simulation results and analysis.

\section{ANTENNA DESIGN \& THEORY}

The geometry of antenna is shown. Fig. 1(b) shows the $1 \mathrm{x} 2$ array of antenna structure. The antenna is a $1 \times 2$ array of Square Monopole Antenna designed on duroid substrate having thickness of $0.787 \mathrm{~mm}$ and dielectric constant $\varepsilon \mathrm{r}=2.2$ and $\tan \delta=0.0009$.

Fig. 1(c) shows the geometry of the FSS layer antenna. The Frequency Selective Surface layer is designed on a FR4 substrate having thickness of $1.6 \mathrm{~mm}$ and dielectric constant $\mathrm{gr}=4.4$ and loss tangent $\tan \delta=0.02$.

For a square monopole antenna, the lower frequency fL corresponding to VSWR $=2$ is calculated by

$\mathrm{f}_{\mathrm{L}}=\frac{c}{\lambda}=\frac{7.2}{(L+r+g)}$

where $\mathrm{L}$ is the height of the monopole antenna in $\mathrm{cm}, \mathrm{r}$ is the effective radius of the equivalent cylindrical monopole antenna in $\mathrm{cm}$ and $\mathrm{g}$ is the gap between ground plane and monopole structure [4].

For a square monopole antenna, the equivalent values of $\mathrm{L}$ and $\mathrm{r}$ are: $\mathrm{L}=\mathrm{S}$ and $\mathrm{r}=\mathrm{S} / 2 \pi$. Then,

$\mathrm{f}_{\mathrm{L}}=\frac{c}{\lambda}=\frac{7.2}{(1.16 S+g)}$

The 1x2-array square monopole antenna is fed through a $50 \Omega$ microstrip line. The Frequency Selective Surface (FSS) layer is placed below the antenna. The distance of FSS layer from the antenna is important for the waves reflected from FSS to be in constructive phase with the waves radiated from the monopole antenna. The Frequency Selective Surface(FSS) layer consists of an array of square patches fabricated on FR4 substrate of 1.6 $\mathrm{mm}$ thickness having dielectric constant $=4.4$ and loss tangent $=$ 0.02 . The gap between the patches acts as a capacitor and the patches act as inductors. Thus, FSS acts as a band pass filter and affects the amplitude and the phase of the fields reflected from this FSS layer. The FSS layer consists of $3 \times 3$ square patch array of length ' $x$ ' each with uniform spacing ' $s$ '. FSS layer has dimensions of $213 \mathrm{~mm} \times 213 \mathrm{~mm}$. The structures are optimized using Zealand IE3D software. The optimum dimensions of antenna are tabulated in Table I. 


\section{MONOPOLE ANTENNA}

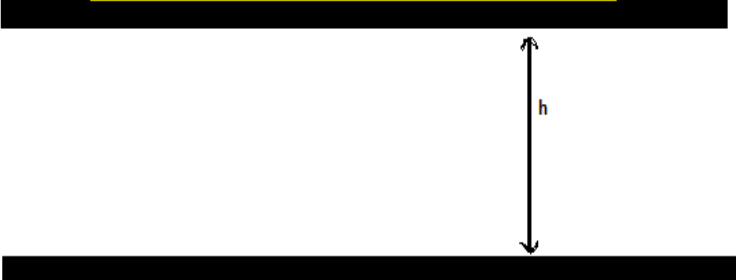

FSS LAYER

(a)

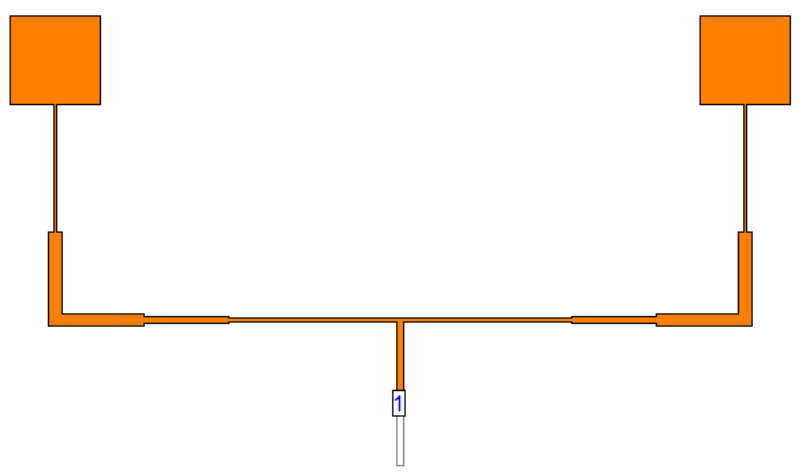

(b)

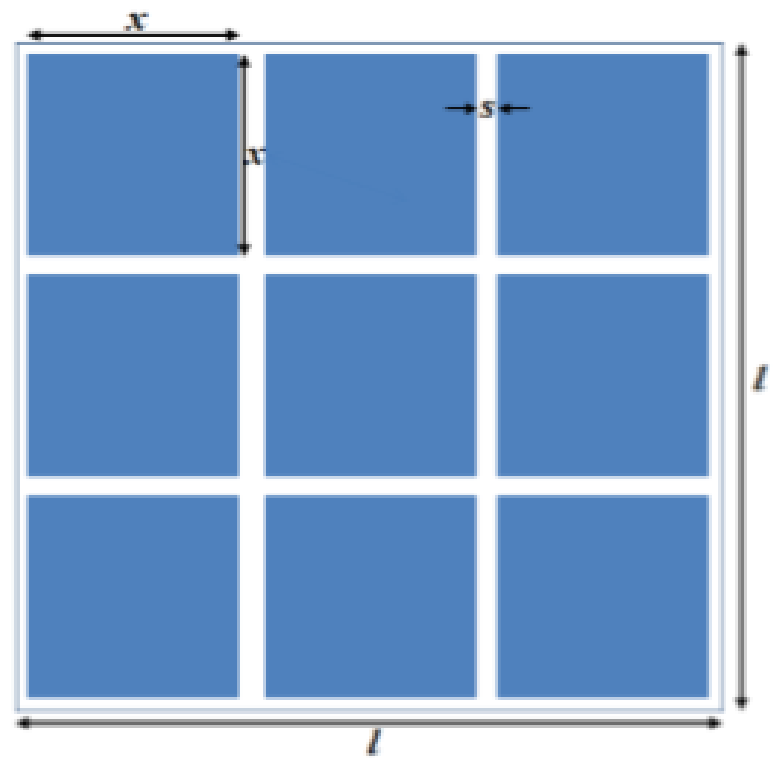

(c)

Fig. 1: (a) Antenna with FSS reflector (b) 1x2-array Square monopole antenna (c) Frequency Selective Surface layer.
TABLE I. Optimum Dimensions (in mm) of Proposed Antenna Structure

\begin{tabular}{|l|l|l|l|l|}
\hline $\mathbf{f}_{\mathbf{L}}(\mathbf{G H z})$ & $\mathbf{x}$ & $\mathbf{g}$ & $\mathbf{h}$ & $\mathbf{s}$ \\
\hline 2.3 & 70 & 0 & 16 & 1 \\
\hline
\end{tabular}

\section{SIMULATION RESULTS \& ANALYSIS}

The Frequency Selective Surface (FSS) layer is placed below the $1 \times 2$ array of square monopole antenna. The $S_{11} \&$ the gain variation between the $1 \times 2$ array of square monopole antenna and FSS reflector for various cases is shown below.

\section{A. Effect of FSS reflector height ' $h$ '}

The $\mathrm{S}_{11}$ and gain variation for different reflector height ' $h$ ' of Frequency Selective Surface layer are shown below in Fig. 2(a) and (b) respectively.

$\mathrm{S}_{11}$ degrades with decrease in reflector height due to mismatch caused by reflections. However, the antenna gain increases with decrease in reflector height. This is due to the increase in effective electrical size of the reflector with decrease in reflector height.

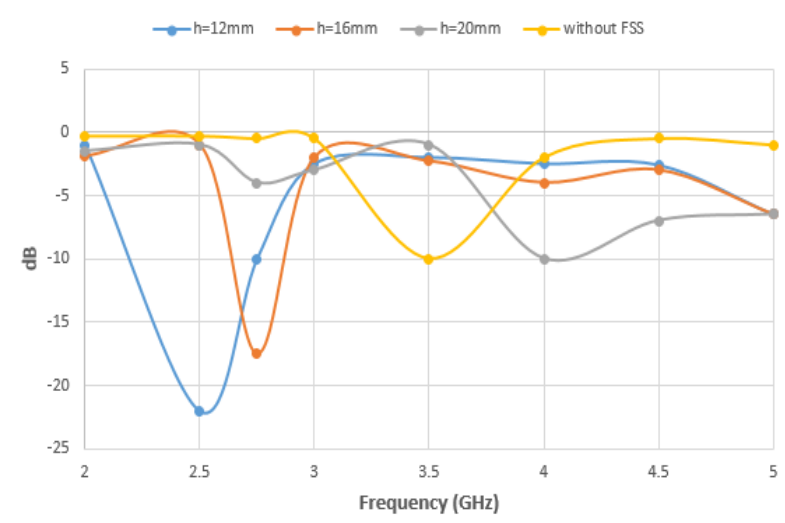

(a)

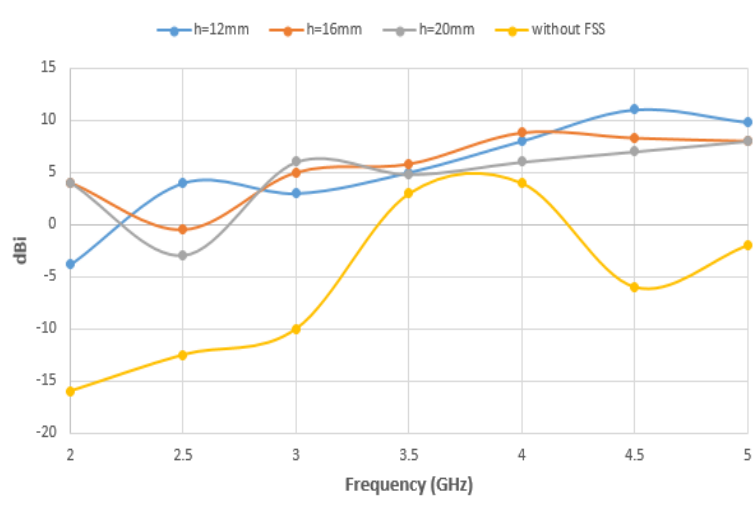

(b)

Fig. 2: (a) $S_{11}$ and (b) Gain vs Frequency variation for different heights ' $h$ ' at $2.3 \mathrm{GHz}$.

\section{B. Effect of patch size ' $x$ '}

The $\mathrm{S}_{11}$ and gain variation for different patch size ' $\mathrm{x}$ ' of Frequency Selective Surface layer are shown below in Fig. 3(a) and (b) respectively. The resonating frequency of the antenna depends on FSS patch size. As the patch size increases the inductance of patch increases, therefore the resonant frequency decreases. FSS patch size also affects the impedance matching 
and gain of the antenna. At higher frequency as the patch size decreases, S11 improves and therefore, maximum gain is obtained.

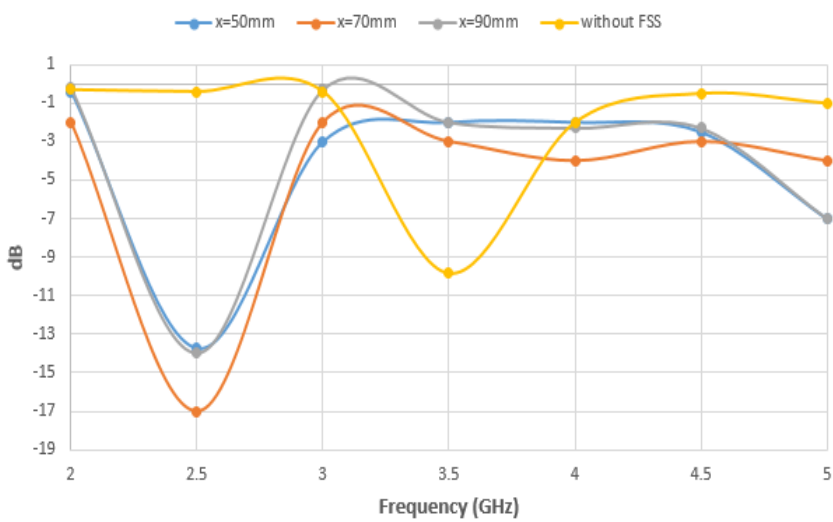

(a)

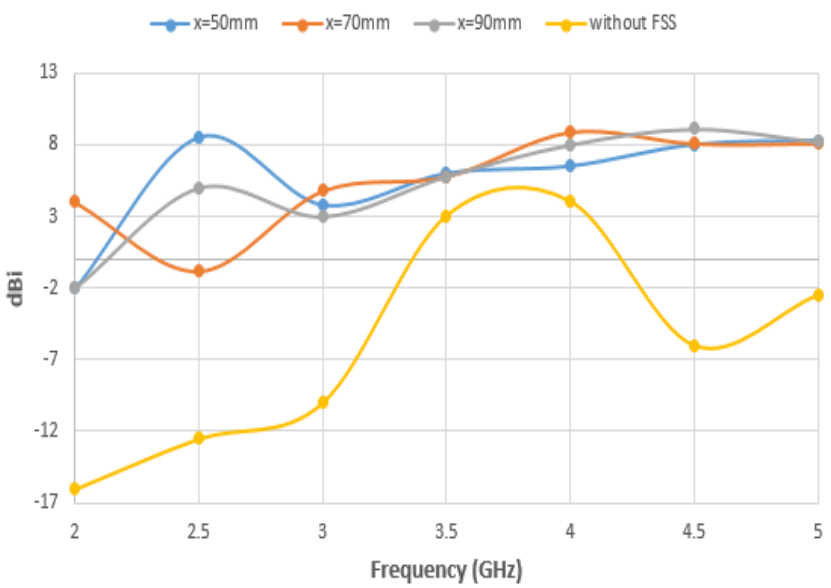

(b)

Fig. 3: (a) $S_{11}$ and (b) Gain vs Frequency variation for different patch size ' $x$ ' at $2.3 \mathrm{GHz}$.

\section{CONCLUSION}

A $1 \times 2$ array of square monopole antenna with a Frequency Selective Surface reflector is proposed. The analysis with respect to FSS reflector height and patch size is done. Maximum gain of $10.2 \mathrm{dBi}$ is obtained when operated at $2.3 \mathrm{GHz}$, which is the WiMAX frequency. This proposed antenna can be used for WiMAX applications as well as various UWB applications.

\section{REFERENCES}

[1] C. Balanis, "Antenna Theory: Analysis and Design", Third edition, 2005.

[2] Gyeong-Ho Kim, Tae-Yeoul Yun, "Compact ultrawideband monopole antenna with an inverted-Lshaped coupled strip," IEEE Antennas and Wireless Propagation Letters, 2013.

[3] Osama M. H. Ahmed and Abdel-Razik Sebak, "Planar ultrawideband antenna array for short-range wireless communications," Microwave And Optical Technology Letters, 52 (5), 1061-1066, 2010

[4] K.P. Ray, "Design Aspects of Printed Monopole Antennas for Ultra-Wide Band Applications", International Journl of Antennas and Propagation, Hindawi Publishing Corporation., 2008.

[5] N. Kushwaha, R. Kumar, "High gain UWB antenna using compact multilayer FSS," IEEE International Microwave and RF Conference (IMaRC), 2014.

[6] Y. Ranga, K. P. Esselle, L. Matekovits, S. G. Hay , "Increasing the gain of a semicircular slot UWB antenna using an FSS reflector," IEEE Conference on Antennas and Propagation in Wireless Communications, APWC), pp. 478-481, 2012

[7] Yogesh Ranga, Ladislau Matekovits, Karu P. Esselle,and Andrew R. Weily , "Multioctave frequency selective surface reflector for Ultrawideband antennas," IEEE Antennas and Wireless Propagation Letters, vol. 10, pp 219-222, 2011.

[8] G. Kumar and K.P. Ray, Broadband microstrip antennas, Artech House, Norwood, MA, 2003.

[9] IE3D Release 14, Zeland Software Inc, Fremont, CA, USA, 2008. 